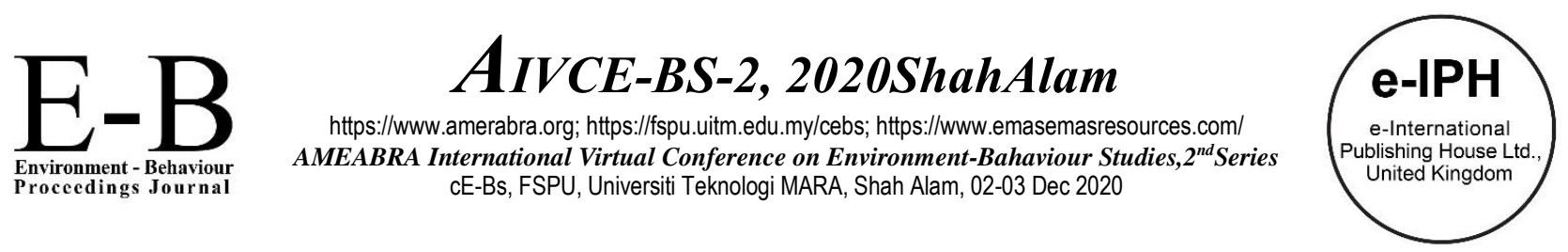

\title{
Comparison of Academic Motivation in Different Phases of Optometry Studies
}

\author{
Noor Halilah Buari, Hendrry Win Alim \\ Centre of Optometry, Faculty of Health Science, \\ Universiti Teknologi MARA Cawangan Selangor, Kampus Puncak Alam, 42300 Bandar Puncak Alam Selangor, Malaysia \\ noorhalilah@uitm.edu.my, hendrrywin_alim96@yahoo.com \\ Tel: +60126121582
}

\begin{abstract}
The changes in motivation cause an impact on students' behavior related to academic success. The online survey found that a significant variation of academic motivation occurred in four different phases of Optometry studies. The $3^{\text {rd }}$ year preclinical students displayed a lack of motivation compared to other student groups. This indicated changes in learning adaptation for different syllabus and approaches in educational stages. The academic performance correspondent with the students' motivation as higher motivation gave better academic performance. Thus, understanding students' academic motivation permits educators to improve the educational approaches in teaching and learning to enhance student performance.
\end{abstract}

Keywords: Motivation; Optometry, Health Sciences, Education

eISSN: 2398-42870 2020. The Authors. Published for AMER ABRA cE-Bs by e-International Publishing House, Ltd., UK. This is an open access article under the CC BYNC-ND license (http://creativecommons.org/licenses/by-nc-nd/4.0). Peer-review under responsibility of AMER (Association of Malaysian Environment-Behaviour Researchers), ABRA (Association of Behavioural Researchers on Asians) and cE-Bs (Centre for Environment-Behaviour Studies), Faculty of Architecture, Planning \& Surveying, Universiti Teknologi MARA, Malaysia.

DOI: https://doi.org/10.21834/ebpj.v5i15.2496.

\subsection{Introduction}

Education plays a vital role in the development of every nation. Transformation in the education system from pre-school to university aimed to boost student ability and performance (Grapragasem et al., 2014; Ministry of Education, 2012). Therefore, the mission is not only focusing on the number of students but also on producing a high quality of students who can cope and generate critical thinking to face the challenges in preparing themselves for job demands. Thus, to achieve success in the education system, the students' academic performance has become a tool of assessment.

Academic motivation is an essential determinant of academic performance and achievement (Elliott \& Dweck, 2005). The selfdetermination theory (SDT) accommodated a theoretical framework in understanding the student's academic motivation (Ryan et al., 2009; Ryan \& Deci, 2000a). SDT suggested a continuum comprised of three types of motivation, intrinsic motivation, extrinsic motivation, and amotivation. Intrinsic motivation is the willingness to pursue the individual's desire, resulting from internal factors such as gratification, interest and enjoyment (Ryan \& Deci, 2000a, 2000b). Intrinsic motivation is considered the most optimal form of inspiration and is associated with various benefits, including determination, students' tenacity, and psychological well-being. Students with intrinsic motivation oriented will not depend on rewards or reinforcement to complete tasks to succeed (Ryan \& Deci, 2000b). Extrinsic motivation is the attraction to achieve something by external factors such as positive and negative reinforcement, rewards, home and learning environment, supportive family, and peer pressures. Few studies viewed that students who exhibited extrinsic motivation when engaging in learning purely to attain a reward or avoid punishment (Del-Ben et al., 2013; Hardré et al., 2006). In correspond to intrinsic and extrinsic motivation, the third type of motivation is amotivation or helplessness motivation. Amotivation is a state of lacking neither intrinsic nor extrinsic motivation to engage in academic activity. Also, characterized as the absence of perceived competence and a failure to value the activity or the outcomes (Ryan \& Deci, 2000b). Most previous studies showed that amotivation had a strong negative

eISSN: 2398-42870 2020. The Authors. Published for AMER ABRA cE-Bs by e-International Publishing House, Ltd., UK. This is an open access article under the CC BYNC-ND license (http://creativecommons.org/licenses/by-nc-nd/4.0/). Peer-review under responsibility of AMER (Association of Malaysian Environment-Behaviour Researchers), ABRA (Association of Behavioural Researchers on Asians) and cE-Bs (Centre for Environment-Behaviour Studies), Faculty of Architecture, Planning \& Surveying, Universiti Teknologi MARA, Malaysia.

DOI: https://doi.org/10.21834/ebpj.v5i15.2496. 
association with good grades (Htoo, 2014; Ryan et al., 2009). This lack of motivation occurs when students could not get positive feedback regarding their academic performance or believe that they have failed on a repetitive basis. Amotivation resulted when the individual perceived himself/herself as incompetent to achieve the intended goal (Ryan \& Deci, 2000b).

Academic motivation changed in a different state of the educational process (da Silva et al., 2018; Del-Ben et al., 2013; Hall et al., 2015). High motivation showed at the beginning of the enrollment compared to the end of studies among students enrolled in the healthcare profession programs, such as Pharmacy and Medicine. This could be due to naïve, excited, and apprehensive students in the first semester (Hall et al., 2015). Year 1 students had high intrinsic and extrinsic motivation but less motivated at the end of the school (da Silva et al., 2018; Wasityastuti et al., 2018). At the end of school, the study showed no increment in depression but the high complaint of worry, which could be due to distress arising from classes and the need for good grades (Del-Ben et al., 2013). Tight timetable, increased demand in the course syllabus, increased perception that the course is challenging than expected when shifted from year 1 to year 4 caused motivation became ups and downs (Del-Ben et al., 2013; Maurer et al., 2012, 2013). The student underwent healthcare professional or medical courses easily to distress that triggered a breakdown in the study (Reed et al., 2011). Changes in the learning climate associated with students' burnout affect academic motivation (Dyrbye et al., 2009).

Student grade point average (GPA) in higher education has been well-accepted globally to understand students' ability, skills, and knowledge and make educational admissions decisions (Klomegah, 2007; Schneider \& Hutt, 2014). It is well-approved that the relationship between academic motivation and academic performance interconnects and complements each other. Academic motivation had a direct link with the academic progress of healthcare or medical students, and it has the most attention to influence the success in education journey (Arbabi et al., 2015; Baker, 2004; Bakhtiarvand et al., 2011; Htoo, 2014; Maurer et al., 2013). The intrinsic motivation correlated positively with good grades as well as an extrinsic motivation among students. Conversely, some researchers found that the absence of motivation or amotivation was negatively affecting academic performance (Arbabi et al., 2015; Htoo, 2014). Students who exhibited low academic motivation showed poor academic achievement (Htoo, 2014; Ryan et al., 2009). Lack of motivational levels caused by the student's behavior, such as low interest and burnout in the study (Maurer et al., 2013; Schaufeli et al., 2002). Students who were amotivated may tale a nonchalant attitude about academic performance, study habits, and class attendance, which would likely lead to a lower GPA (Davis, 2009).

Most of the study researched the association of academic motivation in student academic performance focus on the type of motivation that affected the behavior that leads to academic performance. Less of the study has been executed to assess the relationship between students' academic motivation, specifically on intrinsic motivation, extrinsic motivation, and amotivation in different years of study. Even though several studies conducted and found the student's motivation level in healthcare professionals, they mainly focused on medical students. Yet, the published data on the academic motivation level among Optometry students was minimal. Optometry is a professional health sciences course that combined theoretical, practical, and clinical practice in a single course. The course intended to produce a competent optometrist. It is conducted in four years or eight semesters with a minimum graduating credit of 140 credits (Majlis Optik Malaysia, 2020). The program starts with theoretical or fundamental courses and follows with preclinical laboratory and clinical training in the curriculum structure. The different phases of the education process might cause various effects on student life. Therefore, the current study is designed to identify students' academic motivation in different optometry studies. The second objective was to investigate the correlation of academic motivation with students' academic performance in the university's optometry course.

\subsection{Methodology}

\subsection{Participants}

The study employed an online cross-sectional survey. The Raosoft Sample Size Software was used to calculate sample size from a total population of 192 student Optometry students with a significance of 0.05 . The sample size took an assumption of $50 \%$ of students responded to the online survey. Hundred forty-seven (147) Optometry students of the Faculty of Health Science, Universiti Teknologi MARA (age range: 19-23 years) voluntarily participated in the study. The participants' division was 32 of year 1, 45 of year 2, 36 of year 3 and, 34 of year 4 students. The first-year and second-year students underwent theory-based learning in the first and third semesters, respectively. Meanwhile, the third-year students were students in their preclinical phase and about to start their clinical training. The fourth-year students are denoted by ongoing clinical training students in the Optometry course. The participant included those active and registered students in the Optometry course of UiTM. The study excluded graduate students or post-graduate students from the study.

We conducted the study according to the ethics guidelines and followed the Declaration of Helsinki. The university research ethics committee approved the study (REC/480/18).

\subsection{Instruments}

A validated questionnaire of the Academic Motivation Scale (AMS) was chosen to investigate participants' academic performance (Vallerand et al., 1992). The AMS comprised of three motivation domains, including intrinsic motivation, extrinsic motivation, and amotivation. There were six sub-dimensions in both intrinsic and extrinsic motivation, including intrinsic: curiosity, intrinsic: the wish to accomplished, intrinsic: the wish to obtain experience, extrinsic: regulation of identification, extrinsic: regulation of introjection, and extrinsic: external regulation. The intrinsic: curiosity has 3 items, intrinsic: the wish to accomplished has 4 items, and intrinsic: the wish to obtain experience has 4 items. The extrinsic: regulation of identification has 4 items, extrinsic: regulation of introjection has 5 items, and extrinsic: external regulation has 4 items. Amotivation has 6 items. In total, AMS contained 28 items. 
Intrinsic in sub-dimension of curiosity ask a question such as "Because I experience pleasure and satisfaction while learning new things". The intrinsic: the wish to accomplished ask about "For the pleasure, I experience while surpassing myself in my study". The example of intrinsic: the wish to obtain experience question would be "For the high feeling that I experience while reading on various interesting subjects". The sample item for the extrinsic domain are extrinsic: regulation of identification, "Because eventually, it will allow me to enter the job market in the field that I like"; extrinsic: regulation of introjection, "To prove to myself that I can do better than just a high-school degree"; and extrinsic: external regulation, "In order to get a more prestigious job later on". An example of amotivation item is "Honestly, I don't know why I come to school". AMS used seven Likert scales in each of the items in the survey. The scale ranges from 1 to 7 , with 1 as "does not correspond at all" and 7 represents "corresponds exactly." AMS has high reliability and validity to measure the academic performance among the student (Vallerand et al., 1992)

The participants' academic performance was measured using the current semester Grade Point Average (GPA) result. The GPAs were obtained from the office of University Academic Affairs. Students' GPA was chosen because it has been identified as a strong predictor of university academic performance for a particular semester (Klomegah, 2007).

\subsection{Experimental procedures}

An online, self-administered survey was computed using the google form (www.google.com/forms). Once completed, the google website generated the survey link. The potential participants, Optometry students, received survey link via messaging applications such as WhatsApp or Telegram, or email. The survey stated the objectives of the study to the participants. At first, the survey indicated the participants to tick informed consent participating in this study. We offer confidentiality and anonymity to participants throughout the research. Then, participants filled up the first part of the online survey, which comprised of demographic data. Then participants started to respond to the AMS survey that consisted of 3 domains and six sub-dimensions. In total, the survey encompassed 28 items. The survey took about 20 minutes to complete. As the participants gave their consent, the GPA of the current semester was obtained from the office of University Academic Affairs.

\subsection{Statistical analysis}

The survey data was transferred to Statistical Package for the Social Sciences (SPSS) version 21. The software calculated the AMS score for each sub-dimension in all participants' groups (Year 1, year 2, year 3, and year 4). The score implied the state of motivations among the participants for different sub-dimension.

The SPSS computed survey data into mean, median, standard deviation, and ranges. The data distribution was normally distributed with the Shapiro-Wilk normality test. Therefore, a comparison of academic motivation levels in different phases of Optometry studies was analyzed using one-way ANOVA and post hoc Least Significant Differences test. Then, the Pearson correlation test evaluated the correlation between academic motivation and academic performance.

\subsection{Findings}

A total of 147 Optometry students participated in the study and completed the online survey. This suggested $100 \%$ response rate. There were $22(15 \%)$ males and $125(85 \%)$ females. The mean age of the participants was $22.3 \pm 0.12$ years. The distributions of participants according to year 1 , year 2 , year 3 , and year 4 were $21.1 \%, 31.3 \%, 24.5 \%$, and $23.1 \%$, respectively.

\subsection{Comparison of academic motivation between four different phases of Optometry studies}

The academic motivation across year 1 , year 2, year 3 , and year 4 of Optometry students were evaluated using AMS. Table 1 charted the academic motivation level among optometry students in a different year.

Table 1: The academic motivation score between four different phases in Optometry studies

\begin{tabular}{|c|c|c|c|c|c|}
\hline \multirow[t]{2}{*}{ Domains / Sub-dimensions } & \multicolumn{4}{|c|}{ Academic Motivation (Score \pm SD) } & \multirow{2}{*}{$\begin{array}{l}\text { Statistical analysis } \\
\quad(p \text { values })\end{array}$} \\
\hline & Year 1 & Year 2 & Year 3 & Year 4 & \\
\hline Intrinsic Motivation & $58.3 \pm 11.2$ & $57.8 \pm 12.3$ & $51.2 \pm 15.8$ & $59.4 \pm 11.3$ & $p=0.03^{*}$ \\
\hline Curiosity & $20.6 \pm 3.9$ & $20.0 \pm 4.1$ & $17.4 \pm 5.5$ & $20.9 \pm 4.2$ & $p=0.01^{*}$ \\
\hline The wish to achieve something & $18.5 \pm 3.9$ & $18.7 \pm 4.3$ & $17.0 \pm 5.3$ & $18.6 \pm 4.1$ & $p=0.31$ \\
\hline The wish to obtain experience & $19.2 \pm 3.9$ & $19.2 \pm 4.4$ & $16.8 \pm 5.3$ & $20.0 \pm 3.9$ & $p=0.02^{*}$ \\
\hline Extrinsic Motivation & $59.1 \pm 12.5$ & $61.7 \pm 11.8$ & $55.0 \pm 14.4$ & $62.8 \pm 10.8$ & $p=0.04^{*}$ \\
\hline Regulation of identification & $20.3 \pm 4.3$ & $20.8 \pm 4.4$ & $17.9 \pm 5.2$ & $21.2 \pm 4.2$ & $p=0.01^{*}$ \\
\hline Regulation of introjection & $18.8 \pm 4.7$ & $20.0 \pm 4.4$ & $17.7 \pm 5.3$ & $19.6 \pm 4.5$ & $p=0.17$ \\
\hline External regulation & $20.0 \pm 5.1$ & $20.9 \pm 4.3$ & $19.4 \pm 5.3$ & $22.0 \pm 3.8$ & $p=0.09$ \\
\hline Amotivation & $10.5 \pm 5.0$ & $11.8 \pm 5.6$ & $15.4 \pm 5.5$ & $9.9 \pm 4.8$ & $p<0.01^{*}$ \\
\hline
\end{tabular}

The analysis showed a significant different in intrinsic motivation $(F(3,143)=3.02, p=0.03)$, extrinsic motivation $(F(3,143)=2.76$, $p=0.04)$ and amotivation $(F(3,143)=7.71, p<0.01)$. Post hoc $L S D$ revealed lower motivation scores among year 3 Optometry students in intrinsic and extrinsic motivation domains. The mean difference score for intrinsic motivation domain was -7.11 (year 3 vs. year 1 ), 6.59 (year 3 vs. year 2), and -8.24 (year 3 vs. year 4). The extrinsic motivation domain exhibited lower motivation levels among year 3 
compared to year the year 1 (mean difference $=-4.01)$, year 2 (mean difference $=-6.58$ ) and also year 4 (mean difference $=-7.71)$. Year 3 Optometry students were also found to have higher amotivation score or helplessness motivation than the year 1 (mean difference $=$ 4.92), year 2 (mean difference $=3.58$ ) and year 4 (mean difference $=5.51$ ).

Figure 1 displayed a comparison of academic motivation among year 1, year 2, year 3 and year 4 of optometry student according to sub-dimensions of AMS. In every sub-dimension of motivation, year 3 showed a reduction of motivation levels. However, the study exhibited significantly lower motivation in intrinsic: curiosity $(F(3,143)=4.42, p=0.01)$, intrinsic: the wish to obtain experience $(F(3,143)$ $=3.29, p=0.02)$ and extrinsic: regulation of identification $(F(3,143)=3.68, p=0.01)$.

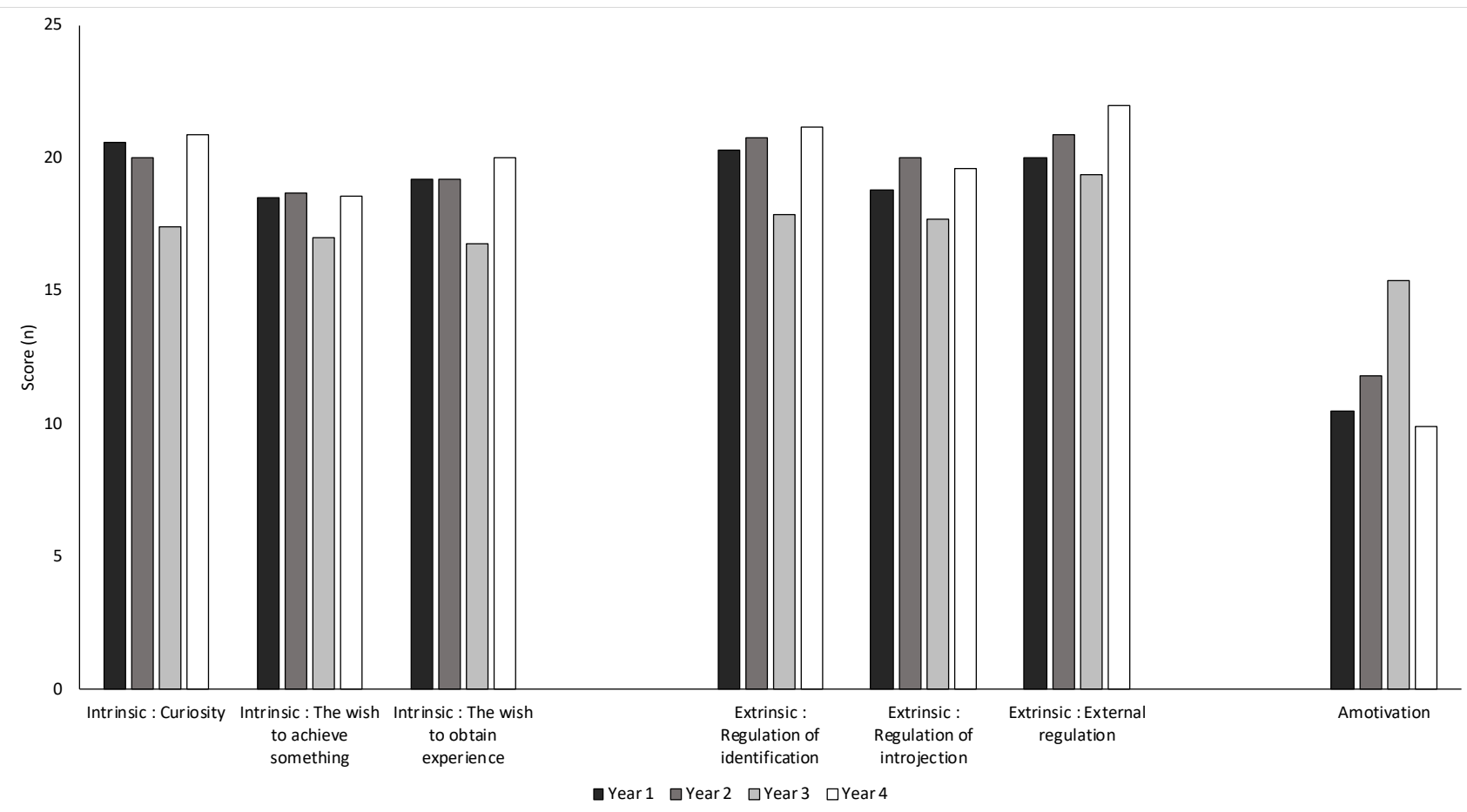

Fig. 1: The comparison of sub-dimensions in AMS between different phases of Optometry studies

\subsection{Correlation of academic motivation with academic performance among Optometry students}

This study's second objective was to investigate the correlation of academic motivation among Optometry students with academic performance. The academic performance indicated with a grade point of average (GPA) for the current semester. The mean of GPA for year 1 was $3.29 \pm 0.24$ points. While the other groups of students showed GPA as $3.20 \pm 0.27$ point for year $2,3.16 \pm 0.28$ point for year 3 , and $3.56 \pm 0.19$ point for year 4 . In total, overall Optometry students had an average of $3.29 \pm 0.29$ points in GPA.

INTRINSIC MOTIVATION

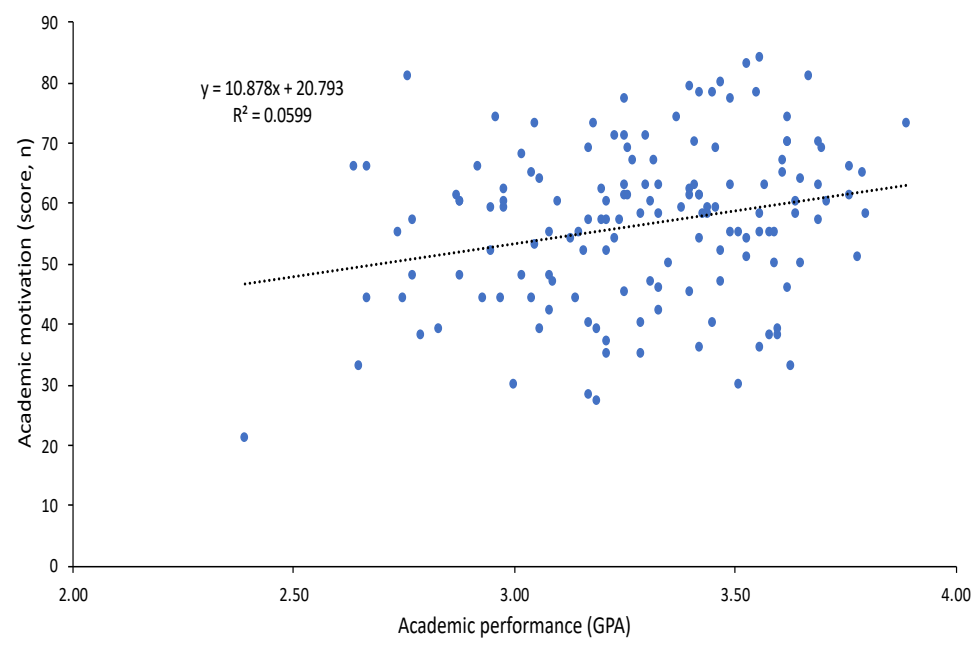




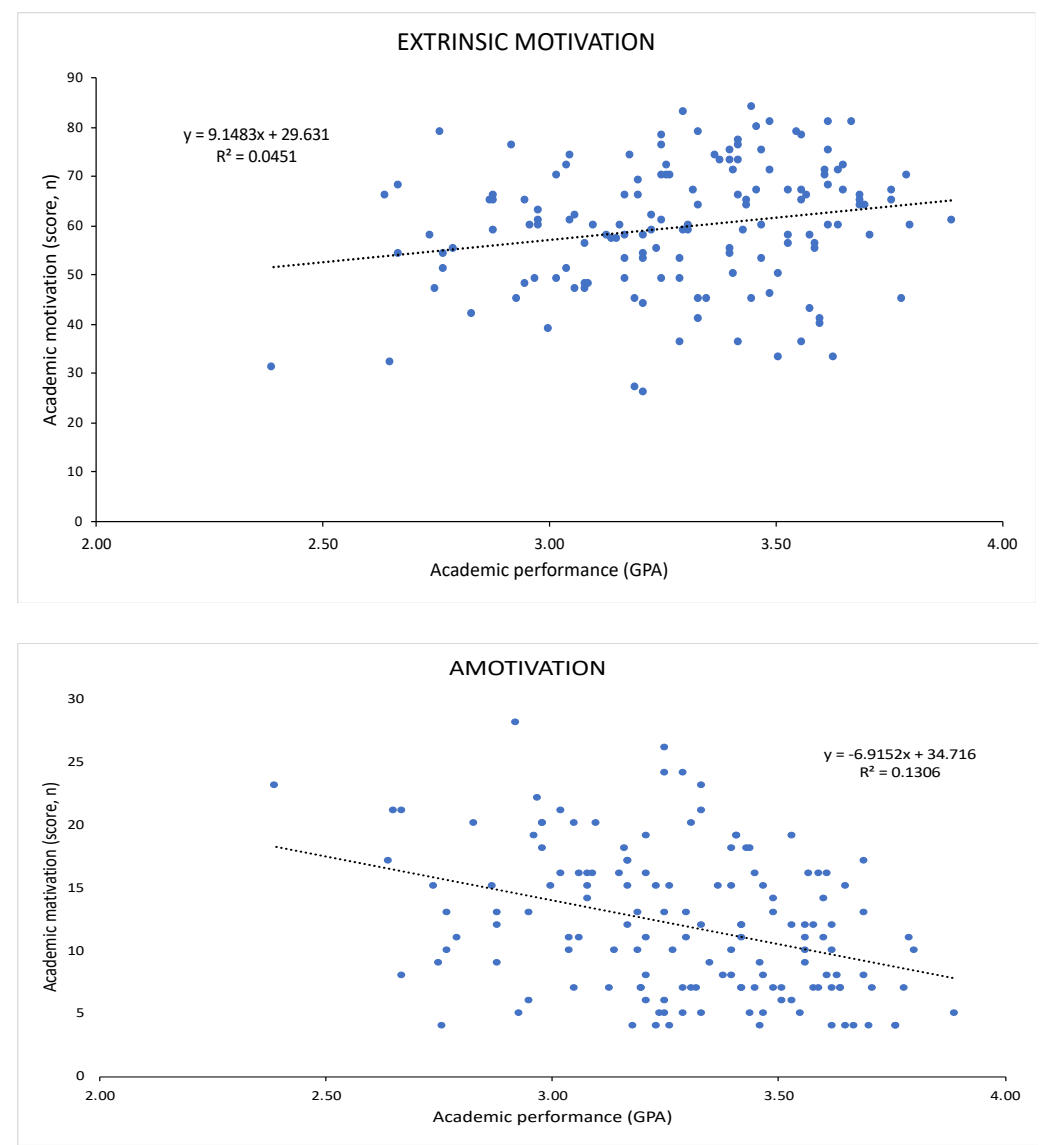

Fig. 2: The scatter of correlation between academic motivation with academic performance among Optometry students. Three motivation domains were intrinsic motivation (above left), extrinsic motivation (above right), and amotivation (below)

The Pearson correlation test exhibited a significant positive correlation $(r=0.25, p=0.003)$ in intrinsic motivation and academic performance. Fig. 2 plotted the scattered correlation of intrinsic motivation, extrinsic motivation, and amotivation with academic performance (GPA). The extrinsic motivation had a significant positive correlation with the GPA among Optometry students $(r=0.21, p$ $=0.01)$. The analysis demonstrated a significant negative correlation between amotivation and academic performance $(r=-0.36, p<$ 0.001). As the students had helplessness motivation, it could significantly affect academic performance.

\subsection{Discussion}

\subsection{Comparison of academic motivation between four different phases of Optometry studies}

The academic motivation level was compared in a different stage of Optometry studies. Results exhibited a significant academic motivation level between year 1, year 2, year 3, and year 4 of Optometry students. The trend of motivation level among Optometry students was high during year 1. However, it started to fall in year 2 and 3 . But, the motivation was raised in year 4 or final year of studies. The lack of motivation occurred among year 3 Optometry students, which they had lower intrinsic motivation and extrinsic motivation. Year 3 Optometry students also demonstrated helplessness of motivation in academic activities. The findings indicated that motivation varied across different phases of 4 years academic course.

Higher motivation at the beginning of the course could be due to excitement to enroll in the course. The students have curiosity, eagerness to accomplish, and experience identification (Del-Ben et al., 2013). Another previous study among Pharmacy and Medical students demonstrated that first-year students performed excellently in academics with goal-oriented compared to third-year students (Hall et al., 2015; Wasityastuti et al., 2018). The motivation reduced in year 2 and dropped significantly in year 3 during the Optometry course. Lack of intrinsic or extrinsic motivation and helplessness of motivation among year 3 students could be since those were preclinical Optometry students. The year 3 students faced preclinical examination in the current semester to get themselves in the clinical year, and coping with classes that mostly combined theoretical and psychomotor could significantly affect their academic motivation. The demands to face clinical examination as challenges could deprive their motivation.

Furthermore, the course was getting complex and challenging as the students shifted from enrollment towards the course's end. This reason implied that year 3 students had a higher score of amotivation compared to year 1, year 2, and year 4 students. High course load, tight schedule, and lack of clinical contextualization between theoretical disciplines and clinical practice could explain students' low motivation (Del-Ben et al., 2013). The students who underwent clinical or medical sciences related courses easily had a high level of 
stress and emotion exhausted, leading to burnout in the study (Reed et al., 2011). The amotivation among allied health students influenced by the less reading, increased perception that the course is difficult than expected, less motivation to accomplish the course, and reduced likelihood of continuing with the current course (Maurer et al., 2012). The similar results demonstrated as a decrease in the self-determined motivation over the various courses of undergraduate studies, which can also be observed in this current study for the third-year students, with higher values of amotivation (Brouse et al., 2010; da Silva et al., 2018; Hakan \& Münire, 2014; Sarkis et al., 2020).

\subsection{Correlation of academic motivation with academic performance among Optometry students}

This study's second objective explored the correlation between academic motivation and academic performance among students of Optometry. Three academic motivation domains (intrinsic, extrinsic, and amotivation) significantly correlated with academic performance (Grade Point Average, GPA) in Optometry students. As the motivation levels boosted, the GPA result became better. However, when the student in the helplessness motivation (amotivation), the GPA is affected reversely. The findings mirrored with previous studies that academic performance or good grades related to academic motivation (Arbabi et al., 2015; Baker, 2004; Bakhtiarvand et al., 2011; Htoo, 2014; Maurer et al., 2013). The GPA is linked to the academic aptitude before entering the university (Baker, 2004). The preclinical medical students' academic grades are also associated with motivation during studies (Isik et al., 2017). Students with absent motivation had poor ability to adjust to university life; thus, trigger more significant psychological distress compared to those with higher motivation (Baker, 2004). Lacking motivation could lead to weaker academic achievement (Htoo, 2014; Ryan \& Deci, 2000a). The motivation also influenced academic behavior in reducing study habits, lack of effort in study, and final performance and grades (Maurer et al., 2013). The amotivation appeared as the only predictor linked to student burnout, which can be a significant factor associated with low academic achievement (Schaufeli et al., 2002). This condition inferred that students with low motivation might suffer from academic burnout and refrain from engaging in academic work, which eventually may result in failure and lower GPA.

We acknowledged the limitation of this study. The survey only involved one institution. The study focused on academic motivation across different years but did not explore the possibility or reasons behind the changes in students' motivational levels. It could be interesting to know the multifactorial reason causing variation in academic motivation that affects the students' academic performance. Overcrowded classrooms, poor quality teaching, insufficient learning facilities, and a chronic shortage of books and equipment make teaching and learning more difficult, negatively affecting students' motivation and drive to pursue education (Hardré et al., 2006). The classroom and school environment can either support or reduce students' academic motivation (Hardré et al., 2006; Ryan \& Deci, 2000a). All findings emphasized that the learning environment to which the students were exposed has a unique relationship with students' academic motivation. We suggested further studies to elucidate the possible causes of this relationship.

\subsection{Conclusion}

In conclusion, a variation of academic motivation occurred in different optometry study phases, especially among the preclinical student. This signified changes in adaptation and reflection for different syllabus and approaches in educational stages. The academic performance correspondent with the students' motivation as higher motivation gave a better academic performance. The study's outcome could assist in planning educational approaches to enhance student academic performance among academic counselors, educators, lecturers, and clinical supervisors.

\section{Acknowledgment}

We would like to thank all the Optometry course (HS246) students who participated and provided the information in this study.

\section{Paper Contribution to Related Field of Study}

This paper could contribute to the educational field of optometry and behavioral optometry which explaining what the students see or perceive with their mind, emotions and behaviors. Thus, it would benefit both students and educator in helping the student to cope with the academic matters.

\section{References}

Arbabi, T., Vollmer, C., Dörfler, T., \& Randler, C. (2015). The influence of chronotype and intelligence on academic achievement in primary school is mediated by conscientiousness, midpoint of sleep and motivation. Chronobiology International, 32(3), 349-357. https://doi.org/10.3109/07420528.2014.980508

Baker, S. R. (2004). Intrinsic, extrinsic, and amotivational orientations: Their role in university adjustment, stress, well-being, and subsequent academic performance. Current Psychology, 23(3), 189-202. https://doi.org/10.1007/s12144-004-1019-9

Bakhtiarvand, F., Ahmadian, S., Delrooz, K., \& Farahani, H. A. (2011). The Moderating Effect of Achievement Motivation on Relationship of Learning Approaches and Academic Achievement. Procedia - Social and Behavioral Sciences, 28, 486-488. https://doi.org/10.1016/j.sbspro.2011.11.093

Brouse, C. H., Basch, C. E., LeBlanc, M., McKnight, K. R., \& Lei, T. (2010). College students' academic motivation: Differences by gender, class, and source of payment. College Quarterly, 13(1), 1-10. 
da Silva, G. M. C., Borges, A. R., Ezequiel, O. da S., Lucchetti, A. L. G., \& Lucchetti, G. (2018). Comparison of students' motivation at different phases of medical school. Revista Da Associação Médica Brasileira, 64(10), 902-908. https://doi.org/10.1590/1806-9282.64.10.902

Davis, G. P. (2009). The relationship between racial identity, motivation, and the academic performance of African American students at a predominately white institution. The George Washington University.

Del-Ben, C. M., Machado, V. F., Madisson, M. M., Resende, T. L., Valério, F. P., \& Troncon, L. E. D. A. (2013). Relationship between academic performance and affective changes during the first year at medical school. Medical Teacher, 35(5), 404-410. https://doi.org/10.3109/0142159X.2013.769675

Dyrbye, L. N., Thomas, M. R., Harper, W., Massie, F. S., Power, D. V., Eacker, A., Szydlo, D. W., Novotny, P. J., Sloan, J. A., \& Shanafelt, T. D. (2009). The learning environment and medical student burnout: A multicentre study. Medical Education, 43(3), 274-282. https://doi.org/10.1111/j.1365-2923.2008.03282.x

Elliott, A. J., \& Dweck, C. S. (2005). Handbook of competence and motivation. Guilford Press.

Grapragasem, S., Krishnan, A., \& Mansor, A. N. (2014). Current Trends in Malaysian Higher Education and the Effect on Education Policy and Practice: An Overview. International Journal of Higher Education, 3(1), 9.

Hakan, K., \& Münire, E. (2014). Academic Motivation: Gender, Domain and Grade Differences. Procedia - Social and Behavioral Sciences, 143, 708-715. https://doi.org/10.1016/j.sbspro.2014.07.469

Hall, M., Hanna, L.-A., Hanna, A., \& Hall, K. (2015). Associations between Achievement Goal Orientations and Academic Performance Among Students at a UK Pharmacy School. American Journal of Pharmaceutical Education, 79(5), 1-7. https://doi.org/10.5688/ajpe79564

Hardré, P. L., Chen, C.-H., Huang, S.-H., Chiang, C.-T., Jen, F.-L., \& Warden, L. (2006). Factors Affecting High School Students' Academic Motivation in Taiwan. Asia Pacific Journal of Education, 26(2), 189-207. https://doi.org/10.1080/02188790600937326

Htoo, H. D. D. M. (2014). Academic motivation and academic achievement of Karen refugee students. Scholar: Human Sciences, 6(2), 41-46.

Isik, U., Wouters, A., ter Wee, M. M., Croiset, G., \& Kusurkar, R. A. (2017). Motivation and academic performance of medical students from ethnic minorities and majority: A comparative study. BMC Medical Education, 17(1), 233. https://doi.org/10.1186/s12909-017-1079-9

Klomegah, R. Y. (2007). Predictors of academic performance of university students: An application of the goal efficacy model. College Student Journal, 41(2), 407-415.

Majlis Optik Malaysia. (2020). Guidelines On Approval And Accreditation Of Optometry And Opticianry Programmes in Higher Education Institutions. Majlis Optik Malaysia.

https://moc.moh.gov.my/borang/Guidelines $\% 200$ n 20 Approval\%20And\%20Accreditation $\% 200$ \%200ptometry $\% 20$ And $\% 200$ pticianry $\% 20$ Programmes $\% 20$ in $\% 20$ Hig her\%20Education $\% 20$ Institutions.pdf

Maurer, T., Allen, D., Gatch, D. B., \& Shankar, P. (2013). A comparison of student academic motivations across three course disciplines. Journal of the Scholarship of Teaching and Learning, 13(5), 77-89.

Maurer, T., Allen, D., Gatch, D. B., Shankar, P., \& Sturges, D. (2012). Students' Academic Motivations in Allied Health Classes. The Internet Journal of Allied Health Sciences and Practice, 10(1), 1-12.

Ministry of Education. (2012). Malaysian Education Blueprint 2013-2025. Ministry of Education Malaysia.

Reed, D. A., Shanafelt, T. D., Satele, D. W., Power, D. V., Eacker, A., Harper, W., Moutier, C., Durning, S., Massie, F. S., Thomas, M. R., Sloan, J. A., \& Dyrbye, L. N (2011). Relationship of Pass/Fail Grading and Curriculum Structure With Well-Being Among Preclinical Medical Students: A Multi-Institutional Study: Academic Medicine, 86(11), 1367-1373. https://doi.org/10.1097/ACM.0b013e3182305d81

Ryan, R. M., \& Deci, E. L. (2000a). Self-Determination Theory and the Facilitation of Intrinsic Motivation, Social Development, and Well-Being. American Psychologist, 11.

Ryan, R. M., \& Deci, E. L. (2000b). Intrinsic and Extrinsic Motivations: Classic Definitions and New Directions. Contemporary Educational Psychology, 25(1), 54-67. https://doi.org/10.1006/ceps.1999.1020

Ryan, R. M., Williams, G. C., Patrick, H., \& Deci, E. L. (2009). Self-determination theory and physical activity: The dynamics of motivation in development and wellness Hellenic Journal of Psychology, 6(2), 107-124.

Sarkis, A.-S., Hallit, S., Haj], A., Kechichian, A., Karam Sarkis, D., Sarkis, A., \& Nasser Ayoub, E. (2020). Lebanese students' motivation in medical school: Does it change throughout the years? A cross-sectional study. BMC Medical Education, 20(1), 94. https://doi.org/10.1186/s12909-020-02011-w

Schaufeli, W. B., Martínez, I. M., Pinto, A. M., Salanova, M., \& Bakker, A. B. (2002). Burnout and Engagement in University Students: A Cross-National Study. Journal of Cross-Cultural Psychology, 33(5), 464-481. https://doi.org/10.1177/0022022102033005003

Schneider, J., \& Hutt, E. (2014). Making the grade: A history of the A-F marking scheme. Journal of Curriculum Studies, 46(2), 201-224 https://doi.org/10.1080/00220272.2013.790480

Vallerand, R. J., Pelletier, L. G., Blais, M. R., Briere, N. M., Senecal, C., \& Vallieres, E. F. (1992). The Academic Motivation Scale: A Measure of Intrinsic, Extrinsic, and Amotivation in Education. Educational and Psychological Measurement, 52(4), 1003-1017. https://doi.org/10.1177/0013164492052004025

Wasityastuti, W., Susani, Y. P., Prabandari, Y. S., \& Rahayu, G. R. (2018). Correlation between academic motivation and professional identity in medical students in the Faculty of Medicine of the Universitas Gadjah Mada Indonesia. Educación Médica, 19(1), 23-29. https://doi.org/10.1016/j.edumed.2016.12.010 